\title{
Experimental study and modelling of abrasive water jet cutting of aluminum alloy 2024
}

\author{
Original \\ Tawfik El Midany ${ }^{1}$, Tarek M. Ahmed ${ }^{2}$, Ahmed S. El Mesalamy ${ }^{3}$, Amro M. Youssef $^{4}$ \\ Article \\ ${ }^{1}$ Department of Manufacturing and Industrial Engineering, Mansura University, \\ Mansoura, ${ }^{2}$ Space Technology Center, Cairo, ${ }^{3}$ Department of Mechanical Design and \\ Manufacturing, Military Technical College, ${ }^{4}$ Head of Mechanical Branch, Military \\ Technical College, Cairo, Egypt.
}

\section{Keywords:}

Abrasive waterjet machining, machining of aluminum alloy, non-traditional cutting, statistical modeling.

\section{Corresponding Author:}

Tarek M. Ahmed, Space Technology Center, Cairo, Egypt, Tel: 01018700730

Email: ta_rek@mail.ru.

\begin{abstract}
Abrasive water jet (AWJ) machining is considered as one of the most powerful cutting processes. It can be used for cutting heat sensitive, hard and reflective materials. It can cut thin sheets to very thick plates. Aluminum 2024 is widely used in aerospace and aviation industries. The objective of this study is to investigate the effect of AWJ control parameters on surface geometry quality. Design of experiments (DoE) is used for establishing an experimental matrix. Statistical modeling is implemented to control the process behavior. It is used to present a relation between the cutting parameters (pressure, speed, and distance between nozzle and cut surface) and responses (taper angle and surface roughness). The taper kerf angle can be improved by decreasing standoff distance and speed, and increasing water pressure. While decreasing (cutting speed, pressure and distance between nozzle and cut surface) improve the surface roughness in the operating window of cutting parameters.
\end{abstract}

\section{INTRODUCTION}

Aluminum alloy 2024 has varied applications, because of its fatigue resistance. It is widely used in aircrafts, especially wings and fuselage structures under tension ${ }^{[1]}$. Additionally, it is used for aircraft fittings, truck wheels, and some parts in transportation industry. Most of these applications depend on large plates processing. AWJ cutting technique can use a very high cutting speeds compared with conventional cutting process especially with thick sections, which will improve the productivity. However, controlling the quality of cutting surface by using AWJ cutting technique is considered difficult due to interacting control parameters.

Abrasive waterjet cutting is a modern non-traditional cutting process.It is used for cutting hard metallic materials without inducing thermal stresses and heat affected zone on the target material ${ }^{[2-4]}$. AWJ is used effectively for cutting some special alloys which used for satellite structures, such as aluminum alloys with a small cutting forces ${ }^{[5]}$.

Despite that the working ranges of the cutting speed in AWJ cutting process for hard alloys are considered high comparing with conventional machining, the surface quality parameters need more improvement especially for space structures manufacturing ${ }^{[6]}$. Investigating the effect of the control parameters is the key point for improvement the cutting quality of AWJ process ${ }^{[7]}$.
Cutting speed for milling process is very limited compared to AWJ process specially for cutting thick plates. $\mathrm{Xu}$, Jin Yang et al. ${ }^{\left[{ }^{[6]}\right.}$ applied an analytical and experimental investigation on the cutting aluminum alloy 2024-T351, with low and high speed. This study showed that max feed rate equals $1.425 \mathrm{~m} / \mathrm{min}$ for high speed machining.

Many of the previous work concluded that taper angle increases with increase of the jet traverse speed $^{[8-12]}$. Because at high traverse speed, available time for the cutting process decreases. this leads to decrease in the waterjet interaction with material target ${ }^{[2,12]}$.

Hajdarevic et al. ${ }^{[13]}$ and Li, Rongrong et al. ${ }^{[14]}$ observed that the roughness value increases by increasing speed. Also Deepak et al. ${ }^{[15]}$ concluded that at low speed, the available cutting time is enough for a primary cutting and so the secondary cutting (which called smoothing) resulting in good surface roughness. By increasing the speed, the available cutting time is not enough for the jet to perform a secondary cutting action which creates striations, and bad surface roughness.

In practice, kerf taper angle increases with increasing standoff distance ${ }^{[12,16-20]}$. Wang and Wong ${ }^{[19]}$ discussed this trend by jet divergence. As the waterjet loses its kinetic energy when penetrates the target material, consequently outer edge diameter will increase.

Ali, Hussein et al. ${ }^{(21)}$ and Selvan et al. ${ }^{[22]}$ found that roughness value increases with increasing standoff distance 
due to non-homogeneous energy distribution.

It has been concluded that taper angle is decreasing with increasing the water pressure ${ }^{[8,11,12,23,24]}$. When jet water pressure increases, the kinetic energy increases. This tends to increase the abrasive particles momentum, which generates wider bottom kerf. Consequently, taper angle is reduced due to decrease the difference between bottom and top width ${ }^{[23]}$. The effect of pressure on taper angle was found to have an opposite trend when cutting polymer composites $^{[16]}$.

Wang et al. ${ }^{[19]}$ found that behavior of surface roughness is not linear with water pressure. Initially, it decreases with the increase of pressure. With further increase of water pressure, the quality of surface deteriorates dramatically. This was also observed by Kovacevic ${ }^{[25]}$ and Ramulu et al. ${ }^{[26]}$. The pressure increase leads to energy increase in jet outer rim which tends to more irregularities. Consequently, surface is deteriorated as a result of nonhomogeneous energy distribution in the jet region.

Li, Rong. et al. ${ }^{[14]}, \mathrm{M}$. Azmir ${ }^{[27]}$, and Trivedi et al. ${ }^{[28]}$ concluded that the value of surface quality is improved by increasing cutting pressure. The abrasives kinetic energy increases with increasing the pressure, consequently increase the capability of material removal. The same results investigated by Selvan, M. et al. ${ }^{[22,29]}$.

According to previous researches, the influence of control parameters on the taper angle and roughness was studied. However, deep investigation for the effect of these parameters with interactions is not reported clearly ${ }^{[22,27,28,30-32]}$. The effect of the control parameters especially pressure on taper and surface roughness show contradicting conclusions ${ }^{[8,11,12,14,16,19,22-24,27]}$.

The aim of this study is improving the cutting quality (kerf taper angle and surface roughness) of AWJ process by experimental and statistical studies. A mathematical model was established for understanding the behavior of AWJ cutting process for Al alloy 2024. It establishes an acceptable correlation between input parameters and output responses at different cutting conditions.

\section{EXPERIMENTAL SETUP}

The AWJ machine (model CL-510) have been used. Maximum pressure of $420 \mathrm{MPa}$ carried on intensifier (SL VI50). A self-aligning cutting head is controlled by AWJ CAM software. Lantek CAD software was used for create the cutting program for the required pass. The cutting head contains a mixing chamber for mixing the water jet with abrasives. Diameter of the output orifice ranges from 0.1 to $0.3 \mathrm{~mm}$.

\section{II.I. TEST SPECIMENS AND PREPARATION}

The working window of each parameter is specified to cover approximately most of available working range for each control parameter, and according to recommendation of previous work for AWJ cutting process ${ }^{[14,16,22,26-29]}$. A set of screening cutting experiments were done for confirming these recommended ranges.

The initial working window for the selected control parameters is; speed (30-150) $\mathrm{mm} / \mathrm{min},(100-300) \mathrm{MPa}$ pressure, and standoff distance "SOD" (1-3) mm.

Thirty samples are used of aluminum alloy 2024 with thickness of $6 \mathrm{~mm}$. Experiments were executed to estimate the influence of control factors on top width, bottom width, taper angle, and roughness as will be discussed in detail in section 3.

\section{II.II. EXPERIMENTAL PLAN}

The experimental plan depends on changing speed, pressure and standoff distance, while keep abrasives mass flow rate with $(420 \mathrm{~g} / \mathrm{min})$. The abrasive used is super garnet (natural mixture of Almandine garnet) with 80 mesh grain size.

Cutting process with AWJ was carried out with a single pass jet on the target samples. Taper was measured by the MitutoyoTM optical microscope.

The kerf width values were measured at top and bottom surfaces of each sample. Five readings were recorded for each level spaced by $5 \mathrm{~mm}$. The kerf taper angle is calculated for each specimen according to average value of top and bottom kerf width readings with the equation below. AWJ generated surface is shown in Figure 1.

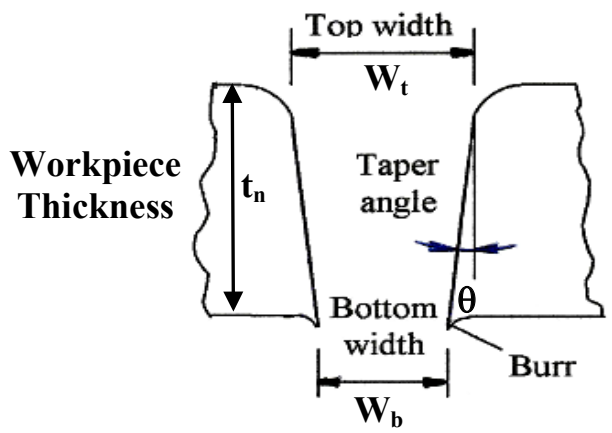

Fig. 1: AWJ generated surface.

Where,

$$
\begin{array}{ll}
\theta: \text { Kerf taper angle } & \mathrm{t}_{\mathrm{n}}: \text { Workpiece thicknes } \\
\mathrm{W}_{\mathrm{t}} \text { : Top width } & \mathrm{W}_{\mathrm{b}}: \text { Bottom width }
\end{array}
$$

Taper angle is calculated via following equation

$$
\Theta=\tan ^{-1}\left[\frac{w_{t}-w_{b}}{2 t_{n}}\right] \quad \text { Eq. } 1
$$

The roughness value $(\mathrm{Ra})$ is measured by using the instrument "TAYLOR HOBSON" (Surtronic 25).

The surface roughness parameter $\mathrm{Ra}$ (center line average parameter) was measured at 3 levels; top, bottom and middle for each machined surface. Surface roughness value is assigned for each specimen depending on the average values of the $\mathrm{Ra}$ at all levels. The surface roughness evaluation span was $=5 \mathrm{~mm}$ per each read. Then, value was calculated and referenced to the mid- 
distance. Five different reads were applied for three levels. The total readings were 15 readings per specimen. The absolute $\mathrm{Ra}$ value of each specimen is the average of all 15 readings. Figure 2 is showing the profile of surface roughness for sample experiment No. 9 as an example.

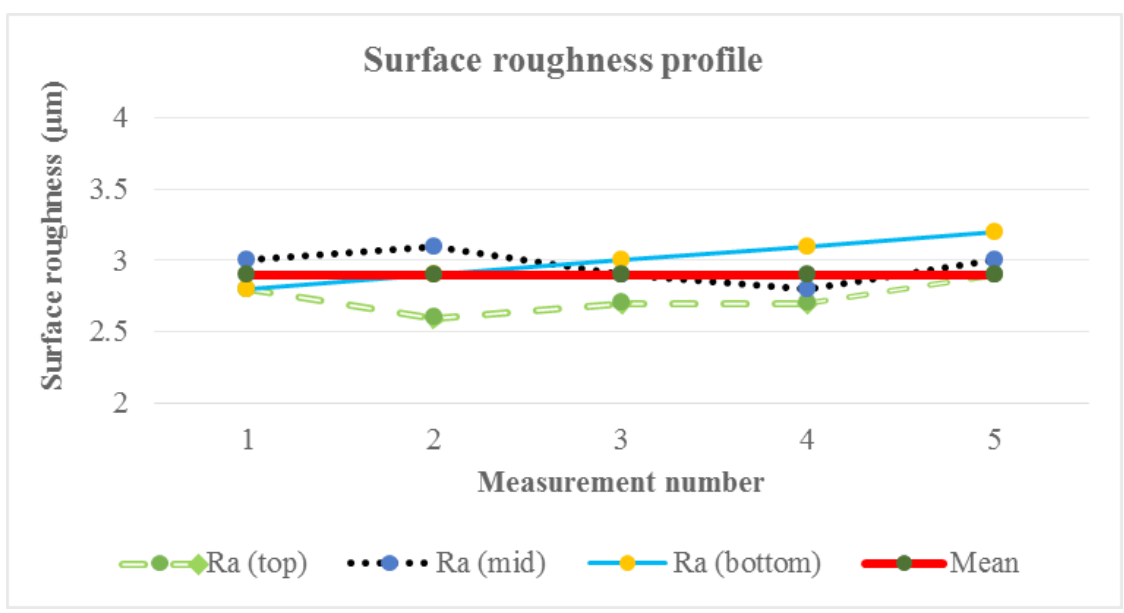

Fig. 2: Profile of surface roughness at three levels (run no. 9)

\section{STATISTICAL MODELLING}

Implementation of the control model of AWJ cutting process was carried out by using Design Expert ${ }^{\circledR}$ software. Design of experiment was applied to identify the experimental matrix to implement the control model.

Response surface method (RSM) is used for modelling and expecting the responses behavior with respect to input variables. It consists of statistical and mathematical techniques. It is useful tool for investigating the effect of control parameters with interactions on the different responses $^{[28,33]}$. RSM depends on fitting order (linear, interacting, squared, or cubic). Required number of experiments is increased by increasing the order of fitting model. In this study a modified cubic order model was used by excluding non-significant factors. The total experiments are 30 runs.

Central Composite Design (CCD) technique is used to identify number of experiments within the experimental matrix according to number of design levels and order of fitting mode ${ }^{[34]}$. CCD depends on two different bases of design the experiments, (three levels base or five levels base). It can be represented graphically with a square for 2 control factors and with a cube for 3 control factors as shown in Figure 3. There are three types of design points (points of applying cutting experiments with different parameters) central, axial, and factorial.

Central point is labelled by star at mid-value of the control parameters. Factorial points are at the both ends of the range for each control parameter, and labeled with red circle. Axial points are labeled with blue circle with redcross as shown in Figure 3. Axial points have 3 possible positions according to value of $(\alpha)$, which is defined by a coded value. If value of $\alpha=1$, the points are on the cube surface (called: surface design). These factors have three levels $(-1,0,1)$. If the value of $\alpha$ is more than one, the axial point is outside the cube and extra 2 levels are added $(-\alpha, \alpha)$. So, the factor has 5 levels $(-\alpha,-1,0,1, \alpha)$. The present design includes five-levels of design matrix experiments $(-1.68,-1,0,1,1.68)$ as shown in Table 1 . The design of experiment will include runs at: 8 points on the corners of cube (factorial), 6 points on the surfaces (axial), and one point in the center (center), Number of runs will be 15 cut with 2 repetitions for each cut. Consequently, the total number of runs are 30 cuts as revealed in Figure 3.
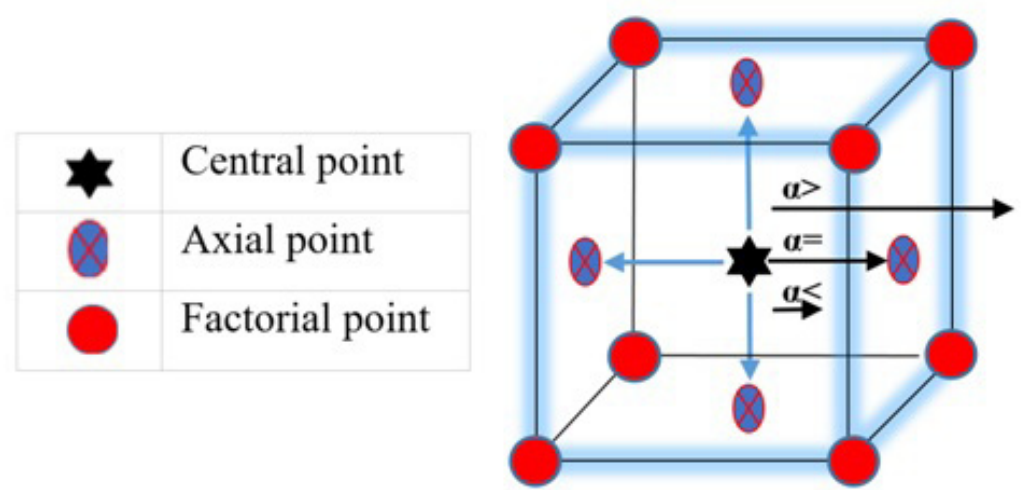

Fig. 3: Central Composite Design (CCD) cube. 
The control parameters are: A: speed $(\mathrm{mm} / \mathrm{min})$, $\mathrm{B}$ : pressure $(\mathrm{MPa})$, and $\mathrm{C}$ : distance between nozzle and cut surface (SOD) (mm). The responses are: R1: upper kerf width (mm), R2: lower kerf width (mm),
R3: taper angle $\left({ }^{\circ}\right)$, and R4: surface roughness $\mathrm{Ra}(\mu \mathrm{m})$. The experimental data are presented in Table 1. R3 is a result of $\mathrm{R} 1$ and $\mathrm{R} 2$ by substituting in Eq.1.

Table 1: Experimental data

\begin{tabular}{|c|c|c|c|c|c|c|c|c|c|c|c|}
\hline \multirow{2}{*}{ Run } & \multirow{2}{*}{ Type } & \multicolumn{2}{|c|}{$\underset{(\mathrm{mm} / \mathrm{min})}{\mathrm{A}}$} & \multicolumn{2}{|c|}{$\begin{array}{c}\mathrm{B} \\
(\mathrm{MPa})\end{array}$} & \multicolumn{2}{|c|}{$\begin{array}{c}\mathrm{C} \\
(\mathrm{mm})\end{array}$} & \multirow{2}{*}{$\begin{array}{l}\mathrm{R} 1 \\
(\mathrm{~mm})\end{array}$} & \multirow{2}{*}{$\begin{array}{l}\mathrm{R} 2 \\
(\mathrm{~mm})\end{array}$} & \multirow{2}{*}{$\begin{array}{l}\mathrm{R} 3 \\
\quad\left({ }^{\circ}\right)\end{array}$} & \multirow{2}{*}{$\begin{array}{c}\mathrm{R} 4 \\
(\mu \mathrm{m})\end{array}$} \\
\hline & & Actual & Coded & Actual & Coded & Actual & Coded & & & & \\
\hline 1 & Axial & 30.00 & -1.68 & 200.00 & 0 & 2.00 & 0 & 1.08 & 1.1 & -0.09 & 2.9 \\
\hline 2 & Axial & 30.00 & -1.68 & 200.00 & 0 & 2.00 & 0 & 1.11 & 1.12 & -0.04 & 2.5 \\
\hline 3 & Fact & 54.32 & -1 & 140.54 & -1 & 2.59 & 1 & 0.98 & 0.98 & 0 & 3.0 \\
\hline 4 & Fact & 54.32 & -1 & 259.46 & 1 & 1.41 & -1 & 1.05 & 1.05 & 0 & 3.2 \\
\hline 5 & Fact & 54.32 & -1 & 140.54 & -1 & 1.41 & -1 & 1.16 & 1.27 & -0.52 & 2.8 \\
\hline 6 & Fact & 54.32 & -1 & 259.46 & 1 & 2.59 & 1 & 1.14 & 1.14 & 0 & 3.8 \\
\hline 7 & Fact & 54.32 & -1 & 140.54 & -1 & 2.59 & 1 & 0.95 & 0.93 & 0.09 & 3.0 \\
\hline 8 & Fact & 54.32 & -1 & 140.54 & -1 & 1.41 & -1 & 0.97 & 0.92 & 0.23 & 3.1 \\
\hline 9 & Fact & 54.32 & -1 & 259.46 & 1 & 2.59 & 1 & 1.11 & 1.11 & 0 & 2.9 \\
\hline 10 & Fact & 54.32 & -1 & 259.46 & 1 & 1.41 & -1 & 1.07 & 1.07 & 0 & 3.1 \\
\hline 11 & Axial & 90.00 & 0 & 200.00 & 0 & 3.00 & 1.68 & 1.08 & 1.01 & 0.33 & 3.7 \\
\hline 12 & Axial & 90.00 & 0 & 200.00 & 0 & 3.00 & 1.68 & 0.99 & 0.99 & 0 & 3.6 \\
\hline 13 & Axial & 90.00 & 0 & 200.00 & 0 & 1.00 & -1.68 & 0.98 & 0.96 & 0.09 & 3.1 \\
\hline 14 & Axial & 90.00 & 0 & 300.00 & 1.68 & 2.00 & 0 & 1.01 & 1.02 & -0.04 & 3.7 \\
\hline 15 & Axial & 90.00 & 0 & 300.00 & 1.68 & 2.00 & 0 & 1.23 & 1.24 & -0.04 & 2.9 \\
\hline 16 & Center & 90.00 & 0 & 200.00 & 0 & 2.00 & 0 & 0.95 & 0.95 & 0 & 3.2 \\
\hline 17 & Axial & 90.00 & 0 & 100.00 & -1.68 & 2.00 & 0 & 0.71 & 0.63 & 0.38 & 4.5 \\
\hline 18 & Axial & 90.00 & 0 & 200.00 & 0 & 1.00 & -1.68 & 0.96 & 0.93 & 0.14 & 3.0 \\
\hline 19 & Center & 90.00 & 0 & 200.00 & 0 & 2.00 & 0 & 1.19 & 1.12 & 0.33 & 4.0 \\
\hline 20 & Axial & 90.00 & 0 & 100.00 & -1.68 & 2.00 & 0 & 0.92 & 0.76 & 0.76 & 4.5 \\
\hline 21 & Fact & 125.68 & 1 & 259.46 & 1 & 1.41 & -1 & 0.95 & 0.95 & 0 & 3.6 \\
\hline 22 & Fact & 125.68 & 1 & 259.46 & 1 & 2.59 & 1 & 1.14 & 1.12 & 0.09 & 3.1 \\
\hline 23 & Fact & 125.68 & 1 & 259.46 & 1 & 1.41 & -1 & 0.95 & 0.97 & -0.09 & 4.3 \\
\hline 24 & Fact & 125.68 & 1 & 140.54 & -1 & 1.41 & -1 & 0.83 & 0.84 & -0.04 & 3.4 \\
\hline 25 & Fact & 125.68 & 1 & 140.54 & -1 & 2.59 & 1 & 0.84 & 0.82 & 0.09 & 3.8 \\
\hline 26 & Fact & 125.68 & 1 & 259.46 & 1 & 2.59 & 1 & 1.16 & 0.96 & 0.95 & 4.0 \\
\hline 27 & Fact & 125.68 & 1 & 140.54 & -1 & 1.41 & -1 & 1.07 & 0.85 & 1.05 & 3.3 \\
\hline 28 & Fact & 125.68 & 1 & 140.54 & -1 & 2.59 & 1 & 0.9 & 0.7 & 0.95 & 3.8 \\
\hline 29 & Axial & 150.00 & 1.68 & 200.00 & 0 & 2.00 & 0 & 1.06 & 0.85 & 1 & 3.6 \\
\hline 30 & Axial & 150.00 & 1.68 & 200.00 & 0 & 2.00 & 0 & 1.04 & 0.88 & 0.76 & 4.0 \\
\hline
\end{tabular}

\section{RESULTS AND DISCUSSION}

This study revealed the effect of the process parameters on the quality of the AWJ cutting process using statistical modelling. Kerf taper angle and surface roughness values were used to evaluate the cutting quality. In experimental study, the surface roughness is measured for side surfaces and perpendicular to waterjet stream direction. Taper angle is calculated as a function of sample thickness, upper, and lower kerf width according to Eq.1.

\section{IV.I MODELLING OF SURFACE ROUGHNESS QUALITY}

The ANOVA results for surface roughness model are shown in (Table 2). It reveals the reduced cubic model variance of surface roughness due to control factors. 
Table 2: ANOVA for surface roughness model

\begin{tabular}{lllllll}
\hline & SS & df & MS & F-Value & $P$-value & significant \\
\hline Model & 4.88 & 5 & 0.98 & 8.65 & $<0.0001$ & 0.0001 \\
A- Speed & 2.42 & 1 & 2.42 & 21.52 & 0.0026 & \\
B- Pressure & 1.27 & 1 & 1.27 & 11.29 & 0.0121 & not significant \\
A2 & 0.83 & 1 & 0.83 & 7.37 & 0.0416 & 0.0024 \\
C2 & 0.52 & 1 & 0.52 & 4.64 & & \\
A2B & 1.30 & 1 & 1.30 & 11.54 & & \\
Residual & 2.70 & 24 & 0.11 & & & \\
Lack of Fit & 0.88 & 9 & 0.098 & 0.81 & & \\
Pure Error & 1.82 & 15 & 0.12 & & & \\
Cor Total & 7.58 & 29 & & & & \\
\hline
\end{tabular}

Values of "Prob $>\mathrm{F}$ " $<0.05$ reveal that model is significant $^{[34]}$. A, B, A2, C2, and A2B are significant. The $\mathrm{P}$-value of $<0.0001$ shows that model is significant. Final equation of roughness model:

$\mathrm{Ra}=3.78+0.30 \mathrm{~A}-0.34 \mathrm{~B}-0.21 \mathrm{~A} 2-0.16 \mathrm{C} 2+0.44 \mathrm{~A} 2 \mathrm{~B} \quad$ Eq. 2

\section{IV.I.I. SURFACE ROUGHNESS MODEL RESULTS AND VERIFICATION}

$\mathrm{Ra}$ value increases with the speed increase
(Figure 4). The high speed decreases the exposure time and machining action between the cutting jet and the target material surface. Increasing standoff distance leads to an increase in surface roughness value as shown in Figure 4. When the jet beam spreads out from the nozzle, the waterjet defocuses and its diameter increases which tends to a decrease of the abrasive particles density in the target area. However, surface roughness value is less sensitive to SOD change with respect to speed change.

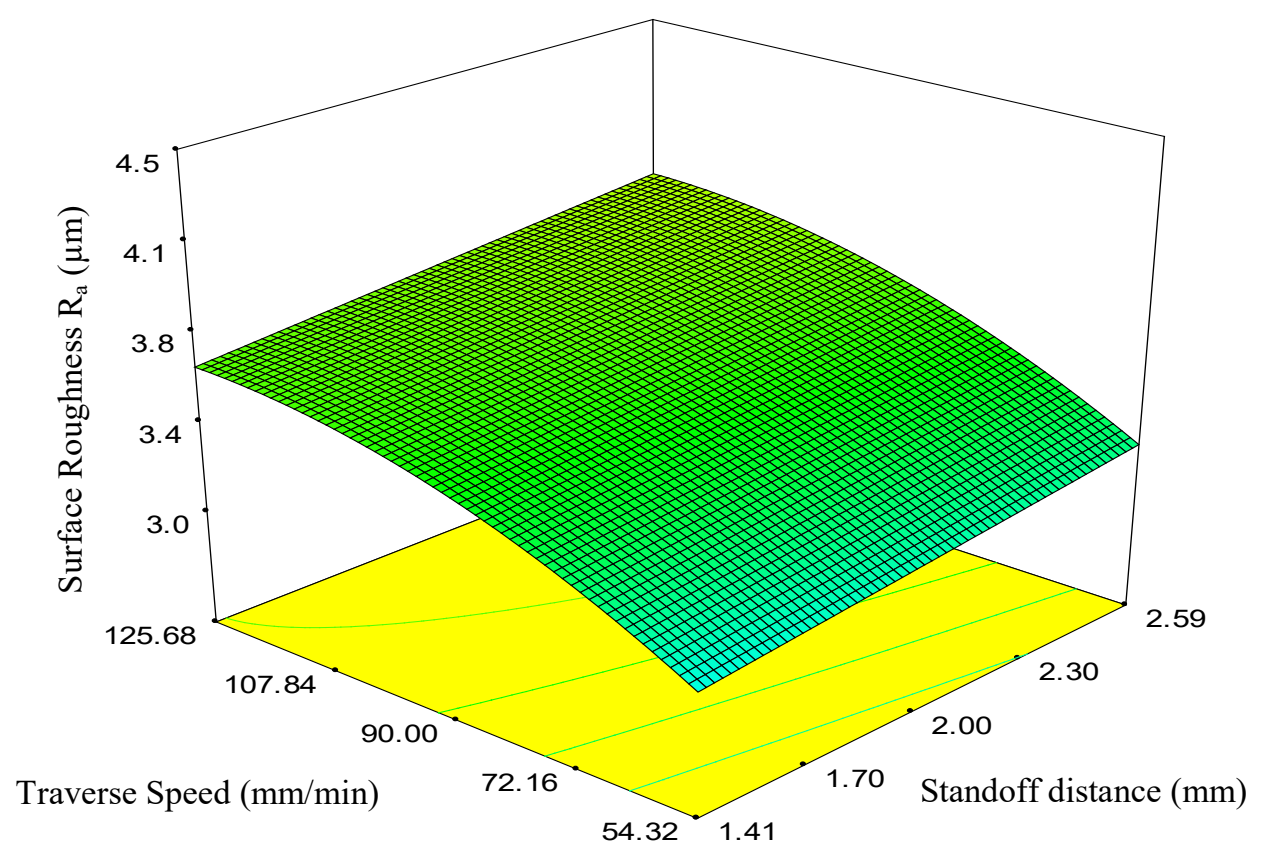

Fig. 4: The interactive effect of speed and SOD on surface roughness. 
Figure 5 shows that the water pressure increase is inversely proportional with surface roughness value. Increasing the water pressure value during cutting leads to unsteadiness of the stream of both water and abrasives which tends to deteriorate the surface. The interaction between pressure and speed (Figure 5) shows that the increase of traverse speed with higher pressure tends to bad surface quality and vice versa. Little exposure time, low machining action, and instability of stream lead to bad surface roughness. Cutting speed is considered the most significant parameters to control the surface quality with respect to other control parameters as shown in Figure 4 and Figure 5. The results revealed tangible improvement of the surface quality of cutting by AWJ with a very high cutting speed with respect to other techniques, consequently productivity ${ }^{[6]}$.

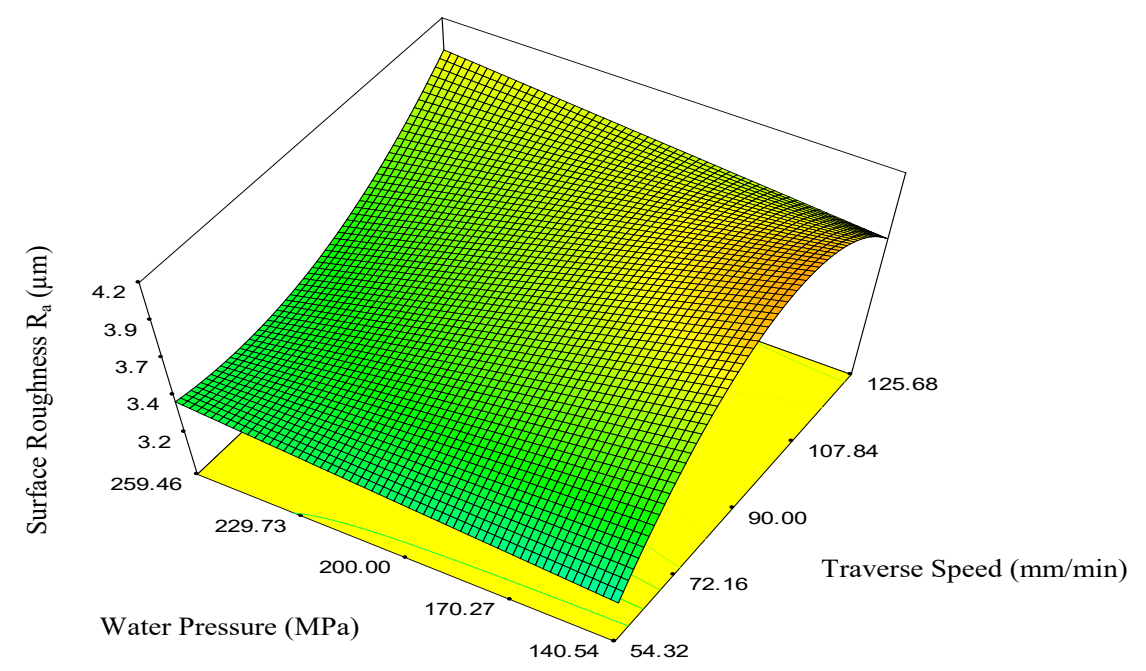

Fig. 5: Interacting behavior of speed and pressure on surface roughness.

Table 3 shows the actual values of surface roughness as measured, and the model prediction values for the surface roughness at all cutting parameters. The model was validated by calculating the model prediction accuracy. It compares the predicted values of surface roughness with the actual measured values. Most of the prediction accuracy for surface roughness exceed $90 \%$ as shown to Table 3 . The average value of the model accuracy is calculated $=92.887 \%$

Table 3: Surface roughness model accuracy

\begin{tabular}{lccccccc}
\hline Exp. No. & $\begin{array}{c}\text { Actual measured } \\
\text { value }\end{array}$ & $\begin{array}{c}\text { Model } \\
\text { prediction value }\end{array}$ & $\begin{array}{c}\text { Model } \\
\text { accuracy }\end{array}$ & Exp. No. & $\begin{array}{c}\text { Actual } \\
\text { measured value }\end{array}$ & $\begin{array}{c}\text { Model } \\
\text { prediction } \\
\text { value }\end{array}$ & $\begin{array}{c}\text { Model } \\
\text { accuracy }\end{array}$ \\
\hline 1 & 2.9 & 2.68 & 92.52 & 15 & 3.2 & 3.78 & 84.6 \\
2 & 2.5 & 2.68 & 93.16 & 16 & 4.5 & 4.35 & 96.69 \\
3 & 3.0 & 3.01 & 99.66 & 17 & 3.0 & 3.32 & 90.13 \\
4 & 3.2 & 3.21 & 99.688 & 18 & 4.0 & 3.78 & 94.5 \\
5 & 2.8 & 3.01 & 93.023 & 19 & 4.5 & 4.35 & 96.69 \\
6 & 3.8 & 3.21 & 84.47 & 20 & 3.6 & 3.81 & 94.48 \\
7 & 3.0 & 3.01 & 99.66 & 21 & 3.1 & 3.81 & 81.36 \\
8 & 3.1 & 3.01 & 97.09 & 22 & 4.3 & 3.81 & 88.60 \\
9 & 2.9 & 3.21 & 90.34 & 23 & 3.4 & 3.61 & 94.18 \\
10 & 3.1 & 3.21 & 96.57 & 24 & 3.8 & 3.61 & 95 \\
11 & 3.7 & 3.32 & 89.95 & 25 & 4.0 & 3.81 & 95.25 \\
12 & 3.6 & 3.32 & 92.456 & 26 & 3.3 & 3.61 & 91.41 \\
13 & 3.1 & 3.32 & 93.13 & 27 & 3.8 & 3.61 & 95 \\
14 & 3.7 & 3.20 & 86.72 & 28 & 3.6 & 3.69 & 97.53 \\
15 & 2.9 & 3.208 & 90.37 & 29 & 4.0 & 3.69 & 92.28 \\
\hline
\end{tabular}




\section{IV.II. THE MODELLING OF TAPER ANGLE}

The results of analysis of variance (ANOVA) for taper angle model are presented in Table 4. It reveals the reduced cubic model variance of kerf taper angle. $P$-value Prob $<\mathrm{F}$ is one of ANOVA significance parameter. If the value of "Prob $>\mathrm{F}$ " is less than 0.05 , the model is significant ${ }^{[34]}$. Results show that terms A, B are significant terms in single form and $\mathrm{C}$ is significant model term in interacting form as shown in Table 4.

Final equation for the control model in terms of significant factors:

Taper Angle $=0.21+0.23 \mathrm{~A}-0.11 \mathrm{~B}+0.096 \mathrm{~A}^{2} \mathrm{C} \quad \mathrm{Eq} .3$

Table 4: ANOVA for kerf taper angle

\begin{tabular}{lcccccc}
\hline & $\begin{array}{c}\text { Sum of } \\
\text { Squares (SS) }\end{array}$ & df & $\begin{array}{c}\text { Mean } \\
\text { Square (MS) }\end{array}$ & $\begin{array}{c}\text { F } \\
\text { Value }\end{array}$ & $P$-value \\
\hline Model & 1.96 & 3 & 0.65 & 6.76 & 0.0006 & Significant \\
A-Traverse Speed & 1.49 & 1 & 1.49 & 15.44 & 0.0016 & \\
B- Pressure & 0.32 & 1 & 0.32 & 3.31 & 0.0406 \\
A2C & 0.15 & 1 & 0.15 & 1.54 & 0.0263 & Not-significant \\
Residual & 2.51 & 26 & 0.097 & & & \\
Lack of Fit & 0.67 & 11 & 0.061 & 0.50 & & \\
Pure Error & 1.84 & 15 & 0.12 & & & \\
Cor Total & 4.47 & 29 & & & & \\
\hline
\end{tabular}

\section{IV.II.I TAPER ANGEL MODEL RESULTS AND VERIFICAITON}

The results of the kerf taper angle control model reveal that SOD is not significant as a single factor. However the interaction between speed and standoff distance is significant.

Figure 6 illustrates interacting effect of the speed and cutting pressure on kerf taper angel. It is clear that taper angle value is directly proportional with cutting speed. At high speed, interacting time available for the cutting process decreases. Finally, at high speed, time could be insufficient for full penetration, this tends to cut on the top kerf wider than in bottom and leads to higher taper angle.

Figure 8 shows that Jet pressure is inversely proportional with kerf taper angel. Pressure Increase leads to increase in the kinetic energy of abrasive particles in main cutting stream. This improves the penetration and generates a wider cut in the bottom. Hence, the width difference between the bottom and top is reduced, which tends to taper angle decrease.

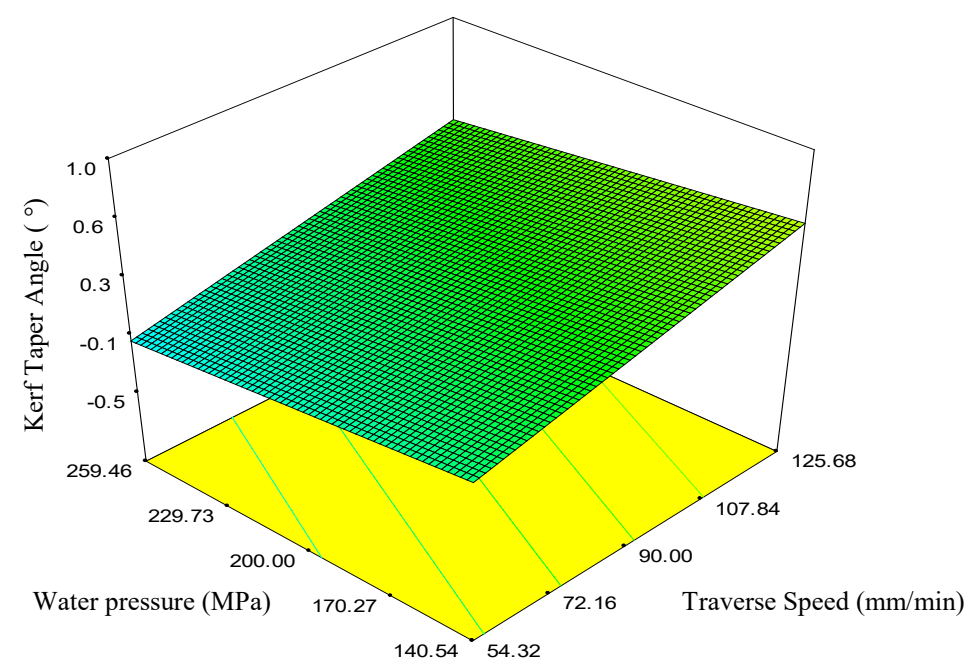

Fig. 6: The interacting influence of speed and pressure on taper angle.

Figure 7 shows that taper angle is inversely proportional with pressure. This behavior is similar to water jet pressure trend as shown in Figure 6, and discussed in previous paragraph. Standoff distance is directly proportional with kerf taper angel with minor effect. Slope of surface graph tends to zero in SOD direction on surface graph as shown in Figure 7. This is mainly due to limited range of SOD. The property of the main cutting stream is approximately constant along specified range of SOD. 


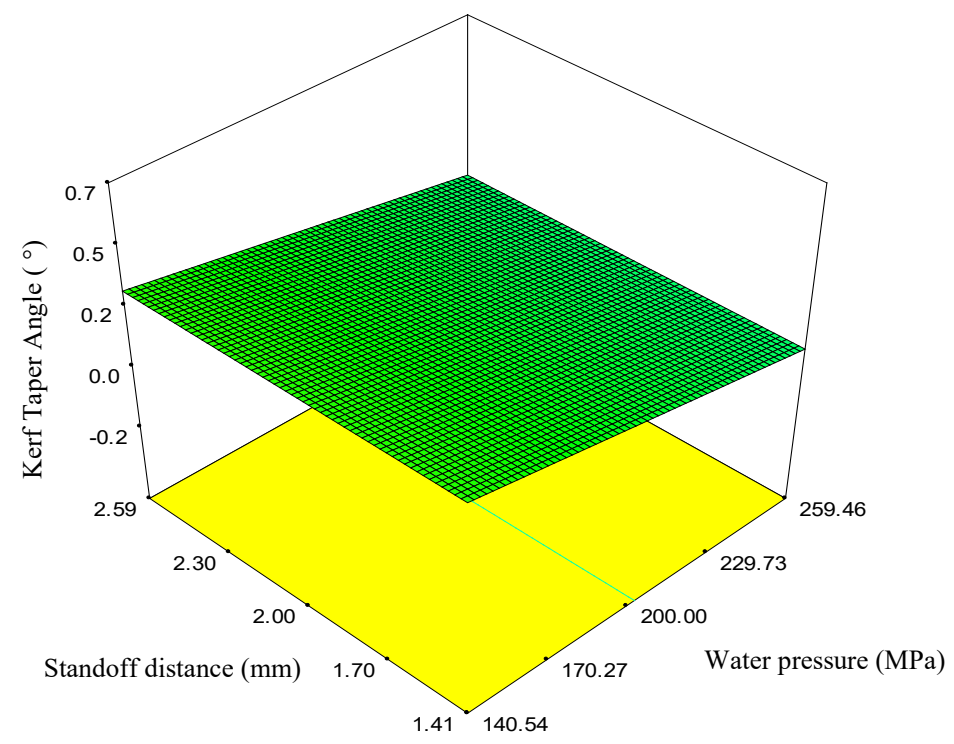

Fig. 7: The interacting influence of pressure and SOD on taper angle.

The interacting influence of speed and SOD on the taper angel is shown in Figure 8. Kerf taper angle increases at high speed and high SOD. Because at higher speed, the available time for cutting decreases, which tends to less interaction time then consequently the particle density per unit length decrease. This leads to less material erosion by abrasives and causes a difference between top and bottom cut surface. When SOD increases, the waterjet loses its kinetic energy and so it has a low energy to affect the lower part of the kerf. It is clear from the control model equation and output surface graphs as shown in (Figure 6, Figure 7 and Figure 8), that kerf taper angel is more sensitive to change in cutting speed with respect to water pressure and stand of distance. Taper angel model shows a good prediction results with respect to actual taper angles with maximum angel deviation less than 0.3 degree.

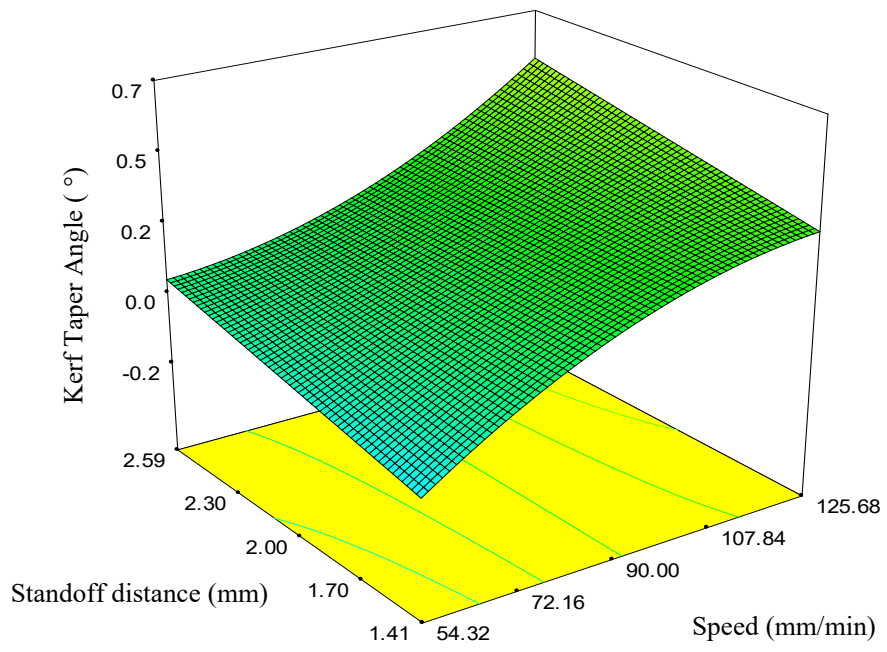

Fig. 8: The interacting influence of speed and standoff distance on kerf taper angle.

\section{CONCLUSION}

- Surface roughness quality and taper angel for AWJ cutting of Al-alloy 2024 were modeled successfully by using statistical modelling.

- Kerf taper angle value is more sensitive to change in cutting speed with respect to water pressure and standoff distance
- Kerf taper angle value can be improved by decreasing the traverse speed and SOD with increasing the water pressure. - Ra value is enhanced mostly by decreasing the water pressure and speed with decreasing the standoff distance. - Cutting speed is considered as the most significant factors to control the taper angel and surface roughness value.

- Experimental data illustrates that, to reach the target of 
best surface roughness value $(2.5 \mu \mathrm{m})$, the applied traverse speed is $30 \mathrm{~mm} / \mathrm{min}$, water pressure is $200 \mathrm{MPa}$, and SOD of $2 \mathrm{~mm}$.

\section{REFERENCES}

[1] R. S. Shevell and R. S. Shevell, Fundamentals of flight vol. 2: Prentice Hall Englewood Cliffs, NJ, 1989.

[2] A. Hascalik, U. Çaydaş, and H. Gürün, "Effect of traverse speed on abrasive waterjet machining of Ti-6Al-4V alloy," Materials and Design, vol. 28 , pp. 1953-1957, 2007.

[3] J. Wang, "A new model for predicting the depth of cut in abrasive waterjet contouring of alumina ceramics," Journal of materials processing technology, vol. 209, pp. 2314-2320, 2009.

[4] J. Folkes, "Waterjet—An innovative tool for manufacturing," Journal of Materials Processing Technology, vol. 209, pp. 6181-6189, 2009.

[5] M. Kahrizi, "Micromachining Techniques for Fabrication of Micro and Nano Structures," ed: InTech, 2012.

[6] J. Y. Xu, Q. L. An, and M. Chen, "Analysis on milling performance of 2024-T351 aluminum alloy using TiAlN coated carbide cutting tools," in Materials Science Forum, 2012, pp. 218-222.

[7] K. Kalpana, O. Mythreyi, and M. Kanthababu, "Review on condition monitoring of Abrasive Water Jet Machining system," in Robotics, Automation, Control and Embedded Systems (RACE), 2015 International Conference on, 2015, pp. 1-7.

[8] D. Arola and M. Ramulu, "A study of kerf characteristics in abrasive waterjet machining of graphite/epoxy composite," Journal of engineering materials and technology, vol. 118, pp. 256-265, 1996

[9] G. Hamatani and M. Ramulu, "Machinability of high temperature composites by abrasive waterjet," Journal of Engineering Materials and Technology, vol. 112, pp. 381-386, 1990.

[10] D. Shanmugam, F. Chen, E. Siores, and M. Brandt, "Comparative study of jetting machining technologies over laser machining technology for cutting composite materials," Composite Structures, vol. 57, pp. 289296, 2002.

[11] V. Gupta, P. Pandey, M. P. Garg, R. Khanna, and N. Batra, "Minimization of Kerf Taper Angle and Kerf Width Using Taguchi's Method in Abrasive Water Jet Machining of Marble," Procedia Materials Science, vol. 6, pp. 140-149, 2014.

[12] D. Shanmugam, J. Wang, and H. Liu, "Minimisation of kerf tapers in abrasive waterjet machining of alumina ceramics using a compensation technique," International Journal of Machine Tools and Manufacture, vol. 48, pp. 1527-1534, 2008.

[13] D. Begic-Hajdarevic, A. Cekic, M. Mehmedovic, and A. Djelmic, "Experimental Study on Surface Roughness in Abrasive Water Jet Cutting," Procedia Engineering, vol. 100, pp. 394-399, 2015

[14] R. Li, M. Ekevad, X. Guo, P. Cao, J. Wang, Q. Chen, et al., "Pressure, Feed Rate, and Abrasive Mass Flow Rate Influence on Surface Roughness for Recombinant Bamboo Abrasive Water Jet Cutting," BioResources, vol. 10, pp. 1998-2008, 2015.

[15] D. Doreswamy, A. Valavala, N. Winitthumkul, and A. Devineni, "Machining of d2 heat treated steel using abrasive water jet: the effect of standoff distance and feed rate on kerf width and surface roughness," International Journal of Research in Engineering and Technology, vol. 3, pp. $417-421,2014$
[16] J. Wang, "A machinability study of polymer matrix composites using abrasive waterjet cutting technology," Journal of materials processing technology, vol. 94, pp. 30-35, 1999.

[17] L. Chen, E. Siores, and W. Wong, "Kerf characteristics in abrasive waterjet cutting of ceramic materials," International Journal of Machine Tools and Manufacture, vol. 36, pp. 1201-1206, 1996.

[18] J. Duflou, J.-P. Kruth, and E. Bohez, "Contour cutting of pre-formed parts with abrasive waterjet using 3-axis nozzle control," Journal of Materials Processing Technology, vol. 115, pp. 38-43, 2001.

[19] J. Wang and W. Wong, "A study of abrasive waterjet cutting of metallic coated sheet steels," International Journal of Machine Tools and Manufacture, vol. 39, pp. 855-870, 1999.

[20] A. A. Khan and M. Y. Ali, Application of Silicon Carbide in Abrasive Water Jet Machining: INTECH Open Access Publisher, 2011.

[21] H. M. Ali, A. Iqbal, and M. Hashemipour, "Experimental Analysis of Hole Making in GFRP Composite Using Abrasive Water Jet Cutting Technology," in Applied Mechanics and Materials, 2013, pp. 1392-1398. [22] M. C. P. Selvan, N. M. S. Raju, and H. Sachidananda, "Effects of process parameters on surface roughness in abrasive waterjet cutting of aluminium," Frontiers of Mechanical Engineering, vol. 7, pp. 439-444, 2012.

[23] D. Shanmugam and S. Masood, "An investigation on kerf characteristics in abrasive waterjet cutting of layered composites," Journal of materials processing technology, vol. 209, pp. 3887-3893, 2009.

[24] A. W. Momber and R. Kovacevic, Principles of abrasive water jet machining: Springer Science and Business Media, 2012.

[25] R. Kovacevic, "Surface texture in abrasive waterjet cutting," Journal of Manufacturing systems, vol. 10, pp. 32-40, 1991.

[26] M. Ramulu, I. Hwang, and V. Isvilanonda, "Quality Issues Associated with Abrasive Waterjet Cutting and Drilling of Advanced Composites," in American WJTA Conference and Expo, Houston, TX, 2009.

[27] M. Azmir and A. Ahsan, "A study of abrasive water jet machining process on glass/epoxy composite laminate," Journal of Materials Processing Technology, vol. 209, pp. 6168-6173, 2009.

[28] P. Trivedi, A. Dhanawade, and S. Kumar, "An experimenta investigation on cutting performance of abrasive water jet machining of austenite steel (AISI 316L)," Advances in Materials and Processing Technologies, pp. 1-12, 2016.

[29] M. C. P. Selvan and N. M. S. Raju, "Analysis of surface roughness in abrasive waterjet cutting of cast iron," International Journal of Science, Environment and Technology, vol. 1, pp. 174-182, 2012.

[30] G. Aydin, I. Karakurt, and K. Aydiner, "An investigation on surface roughness of granite machined by abrasive waterjet," Bulletin of Materials Science, vol. 34, pp. 985-992, 2011.

[31] A. Akkurt, M. K. Kulekci, U. Seker, and F. Ercan, "Effect of feed rate on surface roughness in abrasive waterjet cutting applications," Journal of Materials Processing Technology, vol. 147, pp. 389-396, 2004.

[32] V. Gylienè, V. Jūrènas, and P. Krasauskas, "Investigation of abrasive water jet cutting parameters influence on 6082 aluminium alloy surface roughness," Mechanics, vol. 20, pp. 602-606, 2015.

[33] M. Zohoor and S. H. Nourian, "Development of an algorithm for optimum control process to compensate the nozzle wear effect in cutting the hard and tough material using abrasive water jet cutting process," The International Journal of Advanced Manufacturing Technology, vol. 61, pp. 1019-1028, 2012.

[34] D. C. Montgomery, Design and analysis of experiments: John Wiley and Sons, 2017. 